\title{
Photocatalytic Surface Modification of PI Film for Electroless Copper Plating
}

\author{
Wenxia Zhao $\mathbb{D}^{1},{ }^{1}$ Zenglin Wang, ${ }^{2}$ Liang Qiao, ${ }^{3}$ Shiwei Liu, ${ }^{1}$ Hongjian Zhao, ${ }^{1}$ and Yani Yan ${ }^{1}$ \\ ${ }^{1}$ School of Chemistry and Chemical Engineering, Ningxia Normal University, Guyuan 756000, China \\ ${ }^{2}$ Key Laboratory of Applied Surface and Colloid Chemistry, Ministry of Education, School of Chemistry and Chemical Engineering, \\ Shaanxi Normal University, Xian 710119, China \\ ${ }^{3}$ Department of Chemical and Biological Engineering, University at Buffalo (SUNY), Buffalo, NY 14260, USA
}

Correspondence should be addressed to Wenxia Zhao; zwxchj2006@163.com

Received 21 October 2017; Accepted 12 December 2017; Published 14 January 2018

Academic Editor: Changlin Ding

Copyright (C) 2018 Wenxia Zhao et al. This is an open access article distributed under the Creative Commons Attribution License, which permits unrestricted use, distribution, and reproduction in any medium, provided the original work is properly cited.

This study investigated the surface modification of polyimide (PI) film through $\mathrm{TiO}_{2}$ photocatalytic treatment. The effects of $\mathrm{TiO}_{2}$ content, treatment duration, and UV power on the surface topography, surface contact angle, and adhesion strength of the surface-modified PI films were investigated. The results indicated that, after surface modification under the optimal photocatalytic conditions, the surface contact angle of the PI film decreased from $84.4^{\circ}$ to $38.8^{\circ}$, and the adhesion strength between the PI film and the electroless copper film reached $0.78 \mathrm{kN} / \mathrm{m}$. X-ray photoelectron spectroscopy analysis further demonstrated that carboxyl groups formed on the surface of the PI film after photocatalytic treatment. The surface hydrophilicity and adhesion strength of the surface-modified PI film were enhanced due to the numerous carboxyl groups formed on its surface. Therefore, the photocatalytic treatment is an environmentally friendly and effective method for the surface modification of PI films.

\section{Introduction}

Polyimides (PIs) possess many desirable traits, such as low dielectric constant, high breakdown voltage; good planarization, wear resistance, radiation resistance, inertness to solvents, and hydrolytic stability; low thermal expansion; longterm stability; and excellent mechanical properties. Given these attributes, PIs have been extensively used as substrates in the production of ultra-large-scale integrations, electronic packages, and circuit boards [1-3]. In several of these applications, the deposition of a metal layer on PI substrates is necessary to allow electrical conduction via interconnections [4]. However, poor adhesion strength between the copper film and the PI substrate is a serious problem in these applications.

Over the years, many studies have investigated surface modification methods for improving the adhesion of metals to PI film. The surfaces of PI films are commonly modified through plasma treatment [5-10], ion implantation [11, 12], chemical treatment [13-18], and UV/ozone treatment [1921]. However, physical processes, such as plasma and ion implantation, require expensive equipment and are thus associated with high investment costs. Chemical treatments, such as oxidation, polymer grafting, and etching, require expensive waste disposal. The surfaces of polymers can be modified with photoirradiation, which occurs through the formation of an electron-hole pair in the semiconducting material when the photon energy exceeds the band gap [22]. Photocatalysis has been received increasing attention as an advanced oxidation process due to its low cost and environmental friendliness. In addition, the high chemical stability of $\mathrm{TiO}_{2}$ and the potential use of sunlight as the irradiation source make photocatalysis an attractive method for the surface modification of PI films.

Thomas reported that base hydrolysis and acidification resulted in the formation of poly(amic acid) on the surface of PI film [23]. In this study, we introduced a method that combines the surface formation of hydrophilic species and the cleavage of imide rings to enhance the adhesion of copper to PI film. The effects of $\mathrm{TiO}_{2}$ content $(0.5,1.0,2.5$, and $5.0 \mathrm{~g} / \mathrm{L})$, UV light power (100 and $300 \mathrm{~W})$, and treatment duration $(10,20,30$, and $40 \mathrm{~min})$ on the surface topography, surface roughness, adhesion strength, and surface chemistry of the 
TABLE 1: The compositions of the electroless copper plating bath.

\begin{tabular}{lc}
\hline Composition & Content \\
\hline Copper sulfate $\left(\mathrm{CuSO}_{4} \cdot 5 \mathrm{H}_{2} \mathrm{O}\right)$ & $10 \mathrm{~g} / \mathrm{L}$ \\
Ethylenediaminetetraacetic acid disodium salt & $30 \mathrm{~g} / \mathrm{L}$ \\
$($ EDTA $2 \mathrm{Na})$ & $3 \mathrm{ml} / \mathrm{L}$ \\
Formaldehyde $(\mathrm{HCHO}, 37 \%)$ & $15 \mathrm{mg} / \mathrm{L}$ \\
$2,2^{\prime}$-Dipyridyl & $0.5 \mathrm{~g} / \mathrm{L}$ \\
\hline
\end{tabular}

PI films were investigated. The surface topography and chemistry of the PI films were evaluated through scanning electron microscopy (SEM), atomic force microscopy (AFM), surface contact angle measurements, and X-ray photoelectron spectroscopy (XPS).

\section{Experimental Section}

PI films with a density of $1.42 \mathrm{~g} / \mathrm{cm}^{3}$ were procured from DuPont Chemical Co., Ltd., as Kapton HN in rolls that were $40 \mathrm{~mm}$ wide and $75 \mu \mathrm{m}$ thick. The rolls were then cut into $40 \mathrm{~mm} \times 25 \mathrm{~mm}$ samples for all experiments. Before photocatalytic treatment, the surfaces of the PI films were cleaned with acetone in an ultrasonic water bath for $30 \mathrm{~min}$ at room temperature and washed with deionized (DI) water. The photocatalysis experiments were conducted with a $\mathrm{TiO}_{2}$ suspension over the PI surface. Then, $0.5-5.0 \mathrm{~g}$ of $\mathrm{TiO}_{2}$ powder (JR05, Xuancheng Jingrui New Materials Co., Ltd., $5 \mathrm{~nm}$ ), which was primarily in anatase phase, was dispersed in $1 \mathrm{~L}$ distilled water, respectively. Photocatalytic irradiation was conducted under a high-pressure mercury vapor lamp with a maximum wavelength of $365 \mathrm{~nm}$. The distance between the PI film and the mercury lamp was fixed at $5 \mathrm{~cm}$. After photocatalytic treatment, PI films were rinsed thrice with DI water.

The surface activation of the PI film was carried out in an activation solution (CATAPOSIT 44, purchased from Rohm and Haas Company) at $45^{\circ} \mathrm{C}$ for $5 \mathrm{~min}$. Subsequently, the surface sensitization of the substrates was conducted by immersing the samples in $10 \%$ hydrochloric acid aqueous solution at $30^{\circ} \mathrm{C}$ for $1 \mathrm{~min}$. The PI films were washed with distilled water after each step. The chemical composition of the electroless copper plating solution was the same as that in the literature [18], and the compositions are shown in Table 1. The $\mathrm{pH}$ of the solution was adjusted to 11.5 using $\mathrm{NaOH}$, and the bath temperature was $70^{\circ} \mathrm{C}$. After electroless plating for $40 \mathrm{~min}$, the PIs were electroplated with copper at room temperature with a current density of $0.03 \mathrm{~A} / \mathrm{cm}^{2}$ for $1 \mathrm{~h}$. The copper layer was deposited at a thickness of $20 \mu \mathrm{m}$. After annealing at $100^{\circ} \mathrm{C}$ for $120 \mathrm{~min}$ in an oven, the copper-coated PI films were cut into $10 \mathrm{~mm} \times 40 \mathrm{~mm}$ strips. The adhesion strength of the PI films was measured through a $90^{\circ}$ peel test at a peel rate of $25 \mathrm{~mm} / \mathrm{min}$ [24]. The peel test was repeated four times, and the adhesion strength was reported as the average value of four measurements.

The surface topographies of the PI films were observed through SEM (Philips-FEI Quanta 200 electron microscope).

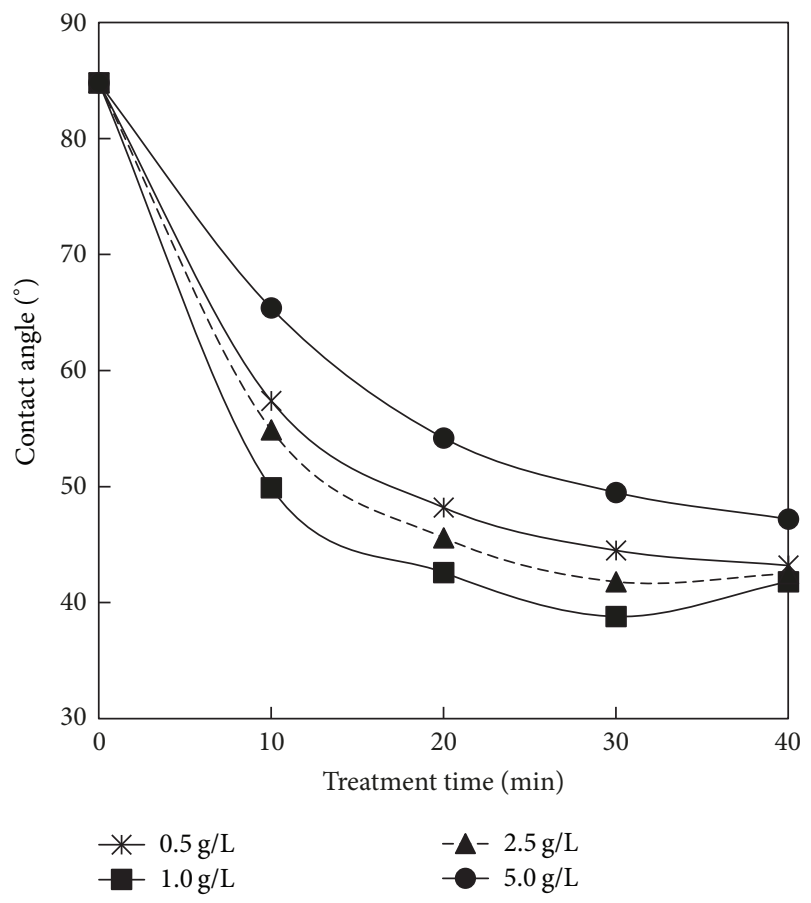

FIGURE 1: Dependence of the surface contact angle upon the $\mathrm{TiO}_{2}$ content and the treatment time under $300 \mathrm{~W}$ UV light.

Moreover, the surface roughness of the PI films was measured through AFM (WETSPM-9500-J3, Shimazu Co., Ltd.). Surface roughness was reported as average roughness $\left(R_{\mathrm{a}}\right)$ and root-mean square roughness $\left(R_{\mathrm{ms}}\right)$. The surface contact angles of the PI films were determined as quickly as possible after different time photocatalytic treatment with a videobased contact angle measurement instrument. The volume of the water drop used in the measurements was $2 \mu \mathrm{L}$, and measurement values were taken at least five positions on the surface of the samples and averaged. The surface composition and chemistry groups of the PI films were determined by XPS measurements taken with a JPS90-MXV spectrometer from JEOL with a nonmonochromatized $\mathrm{Mg} \mathrm{Ka}$ X-ray source. All binding energies were corrected on the basis of the $\mathrm{Cls}$ binding energy at $285 \mathrm{eV}$ [25].

\section{Results and Discussions}

3.1. Effects of UV Power and Treatment Time on the Surface Contact Angle of PI Films. The wettability of the PI films was evaluated by measuring the surface contact angles of the film at room temperature. When the UV power was $300 \mathrm{~W}$, effects of the $\mathrm{TiO}_{2}$ content and the treatment duration upon the surface contact angle were measured, and the results are shown in Figure 1. As seen in the figure, the surface without photocatalytic treatment PI film was hydrophobic. The contact angle between distilled water and the untreated PI film was $84.8^{\circ}$. The surface contact angle of the PI film continuously decreased with increasing treatment duration when the PI films were treated with $0.5 \mathrm{~g} / \mathrm{L} \mathrm{TiO}_{2}$ suspension under $300 \mathrm{~W}$ of UV light, suggesting that $0.5 \mathrm{~g} / \mathrm{L} \mathrm{TiO}_{2}$ content 


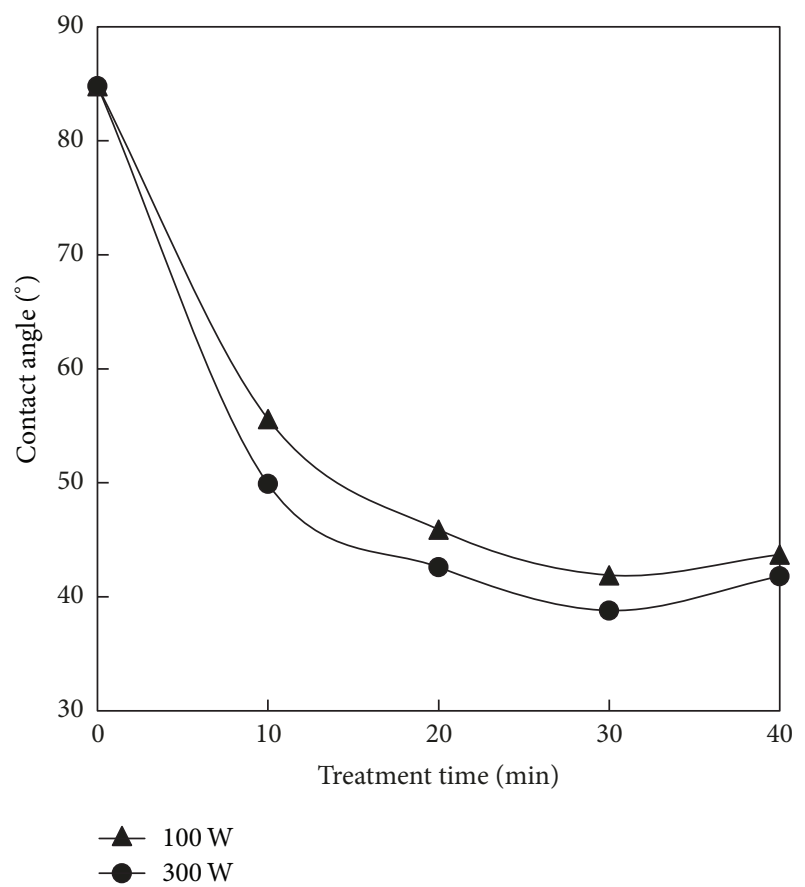

FIGURE 2: Dependence of the surface contact angle upon UV power and the treatment time at the $\mathrm{TiO}_{2}$ content of $1.0 \mathrm{~g} / \mathrm{L}$.

was insufficient for inducing hydrophilicity. The surface contact angle of the PI film treated with $1.0 \mathrm{~g} / \mathrm{L} \mathrm{TiO}_{2}$ suspension decreased with prolonged treatment duration and reached the minimum value with an irradiation time of $30 \mathrm{~min}$; after that, the surface contact angle slowly increased with the further increase in the irradiation time. This result indicated that photocatalytic treatment induced the hydrophilicity of the PI film surface. Meanwhile, the surface contact angle of PI film treated with $1.0 \mathrm{~g} / \mathrm{L} \mathrm{TiO}_{2}$ suspension was considerably lower than that of the PI film treated with $5.0 \mathrm{~g} / \mathrm{L} \mathrm{TiO}_{2}$ suspension for the same treatment duration. This result was attributed to the agglomeration of $\mathrm{TiO}_{2}$ particles in the saturated $\mathrm{TiO}_{2}$ solution, because agglomeration decreases the oxidative capacity of generated ${ }^{\circ} \mathrm{OH}$ radicals. Under $100 \mathrm{~W}$ of UV light, the change trend in the surface contact angle in response to $\mathrm{TiO}_{2}$ content and treatment duration was similar to that under $300 \mathrm{~W}$ of UV light. The results indicated that $1.0 \mathrm{~g} / \mathrm{L} \mathrm{TiO}_{2}$ suspension and $30 \mathrm{~min}$ of photocatalytic treatment are appropriate process parameters for the surface modification of PI film.

The effects of UV light power and treatment duration on the surface contact angle of PI films treated with $1.0 \mathrm{~g} / \mathrm{L} \mathrm{TiO}_{2}$ solution are shown in Figure 2. Under 100 and $300 \mathrm{~W}$ of UV light, the surface contact angle of the PI film first decreased with prolonged treatment time and reached the minimum value after $30 \mathrm{~min}$ of treatment, and then, the surface contact angle increased when treatment time was continuously prolonged. Furthermore, the surface contact angle decreased with increased UV power at the same treatment time and fixed $\mathrm{TiO}_{2}$ content. One potential reason for this result could be that the oxidation capacity of the photocatalytic system was strengthened by the increased intensity of UV light.
The roughness and hydrophilicity of the film surface affect the surface contact angle of the film. Specifically, the surface contact angle decreases with enhanced surface hydrophilicity and decreases with increasing surface roughness. Therefore, surface morphology and surface roughness observations were performed through SEM and AFM.

3.2. Effects of Surface Modification on the Surface Morphology and the Surface Roughness of PI Substrates. Figure 3 shows the changes in surface morphology before and after surface modification with $1.0 \mathrm{~g} / \mathrm{L} \mathrm{TiO}_{2}$ suspension under 100 or $300 \mathrm{~W}$ UV light. The wet-chemical pretreatment may induce changes in morphology and the removal of weakly cohesive surface material. Thus, the surface morphology of the film is very rough and uneven after wet-chemical pretreatment [26, 27]. However, as shown in Figure 3, the surface morphology of the PI film treated with $1.0 \mathrm{~g} / \mathrm{L} \mathrm{TiO}_{2}$ solution showed almost no change compared with that before photocatalytic treatment. Thus, the electroless copper film was more uniformly deposited through the photocatalytic reaction than through the wet-chemical pretreatment.

The AFM observations of the PI film morphology before and after pretreatment are shown in Figure 4. Before photocatalytic treatment, the PI film surface was flat and clean with $R_{\mathrm{a}}$ and $R_{\mathrm{ms}}$ of 13 and $17 \mathrm{~nm}$, respectively. $R_{\mathrm{a}}$ and $R_{\mathrm{ms}}$ of the PI film modified under $100 \mathrm{~W}$ for $30 \mathrm{~min}$ were 14 and $19 \mathrm{~nm}$, respectively. In addition, $R_{\mathrm{a}}$ and $R_{\mathrm{ms}}$ of the PI film modified under $300 \mathrm{~W}$ for $30 \mathrm{~min}$ were 15 and $21 \mathrm{~nm}$, respectively. The results indicated that increasing UV power does not substantially change the surface topography of the PI films.

\subsection{Effects of Surface Modification on the Adhesion Strength.} The dependence of the adhesion strength on surface modification was investigated, and the results are shown in Figures 5 and 6 . The adhesion strength between the electroless copper film and untreated PI film was zero. After photocatalytic treatment for 10 or $40 \mathrm{~min}$, the adhesion strength between the electroless copper film and PI film increased with the increasing of $\mathrm{TiO}_{2}$ content when the treatment time was fixed. And the adhesion strength between the electroless copper film and PI film reached the highest value after the PI film was treated with $1.0 \mathrm{~g} / \mathrm{L} \mathrm{TiO}_{2}$ suspension. After that, the adhesion strength between the electroless copper film and PI film decreased when $\mathrm{TiO}_{2}$ content was further increased. It can be seen from Figure 6, when PI film was treated with $1.0 \mathrm{~g} / \mathrm{L} \mathrm{TiO}_{2}$ suspension, the adhesion strength between the electroless copper film and PI film increased with the increasing of UV power. Adhesion strength reached the maximum value when the PI film was treated for $30 \mathrm{~min}$. This result was consistent with the changes in the surface contact angle of the PI film in response to $\mathrm{TiO}_{2}$ content, treatment duration, and UV power. Given that hydrophilicity can improve the wettability of the film surface, the overall increased wettability of the PI film improved the intimate contact between the PI substrate and the electroless deposited copper film.

Adhesion strength is dependent not only on the surface roughness but also on surface hydrophilicity or density of 


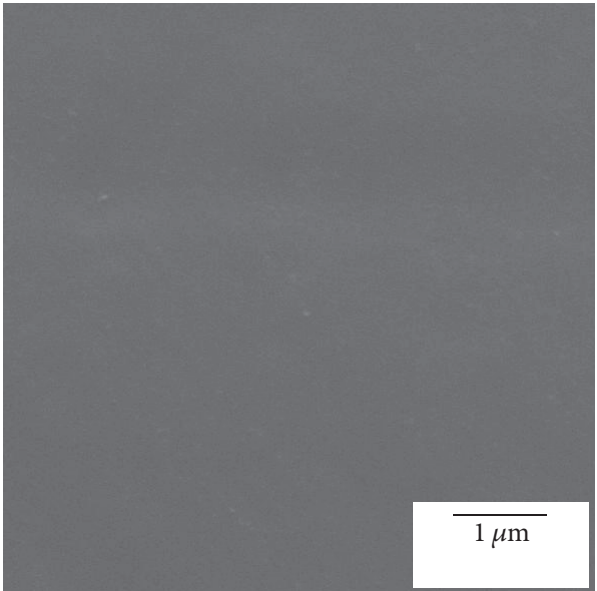

(a)

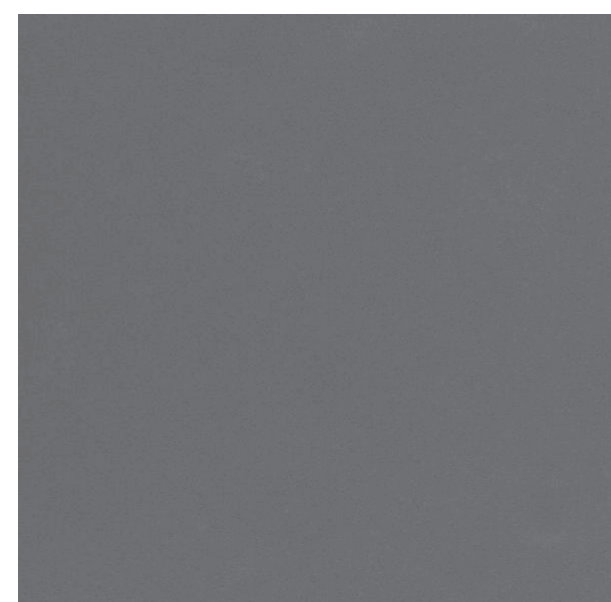

(b)

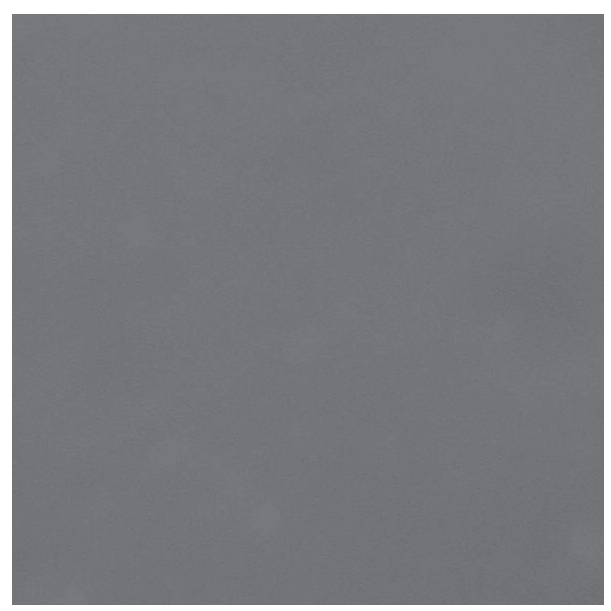

(c)

FIGURE 3: SEM images in surface morphology of PI films before and after surface modification with $1.0 \mathrm{~g} / \mathrm{L} \mathrm{TiO}_{2}$ dispersed solution for 30 min, UV power: (a) $0 \mathrm{~W}$, (b) $100 \mathrm{~W}$, and (c) $300 \mathrm{~W}$.

polar groups. Therefore, the effects of surface modification on the surface chemistry of PI films were investigated.

\subsection{Surface Chemistry of the PI Film before and after $\mathrm{TiO}_{2}$} Photocatalytic Treatment. The surface chemical properties of the PI films before and after photocatalytic treatment were characterized by analyzing the XPS spectra of the PI films. The surface element contents of the PI films were determined through XPS, and the results are shown in Table 2. It can be seen that the carbon content decreased with the increasing UV power and the oxygen content increased with the increasing UV power. The surface carbon and oxygen contents of the untreated PI film were $78.2 \%$ and $15.8 \%$, respectively. When the UV power was $300 \mathrm{~W}$, after $30 \mathrm{~min}$ of photocatalytic treatment, the carbon content of the PI film decreased from $78.2 \%$ to $75.4 \%$, and the oxygen content of the PI film increased from $15.8 \%$ to $19.3 \%$. This result was attributed to the increased density of hydrophilic groups under increased UV power. The trend in the variation of the aforementioned elemental contents corresponded with that of the surface contact angle.
TABLE 2: The element contents of PI surface before and after surface modification with $1.0 \mathrm{~g} / \mathrm{L} \mathrm{TiO}_{2}$ dispersed solution under different UV power.

\begin{tabular}{lccc}
\hline Treatment condition & $\mathrm{C}(\%)$ & $\mathrm{O}(\%)$ & $\mathrm{N}(\%)$ \\
\hline Before treatment & 78.2 & 15.8 & 6.0 \\
$100 \mathrm{~W}, 30 \mathrm{~min}$ & 77.0 & 17.5 & 5.5 \\
$300 \mathrm{~W}, 30 \mathrm{~min}$ & 75.4 & 19.3 & 5.3 \\
\hline
\end{tabular}

The C1s XPS spectra of PI films before and after treated with $1.0 \mathrm{~g} / \mathrm{L} \mathrm{TiO}_{2}$ and UV power of $300 \mathrm{~W}$ were obtained and the results are shown in Figure 7. Four peaks were observed in the spectrum of the PI film before photocatalytic treatment. The peaks at 285.0, 286.2, 288.6, and $291 \mathrm{eV}$ were attributed to $\mathrm{C}-\mathrm{H} / \mathrm{C}-\mathrm{C} / \mathrm{C}=\mathrm{C}, \mathrm{C}-\mathrm{O} / \mathrm{C}-\mathrm{N}, \mathrm{N}(\mathrm{C}=\mathrm{O})_{2}$, and $\pi-\pi^{*}$, respectively. A peak at $289.0 \mathrm{eV}$ appeared in the spectrum of the PI film treated with $1.0 \mathrm{~g} / \mathrm{L} \mathrm{TiO}_{2}$ for 30 min under $300 \mathrm{~W}$ UV light. This peak could be attributed to the $-\mathrm{COOH}$ group. The same phenomenon was observed when the PI film was treated with $1.0 \mathrm{~g} / \mathrm{L} \mathrm{TiO}_{2}$ for $30 \mathrm{~min}$ under $300 \mathrm{~W}$ UV light. The 


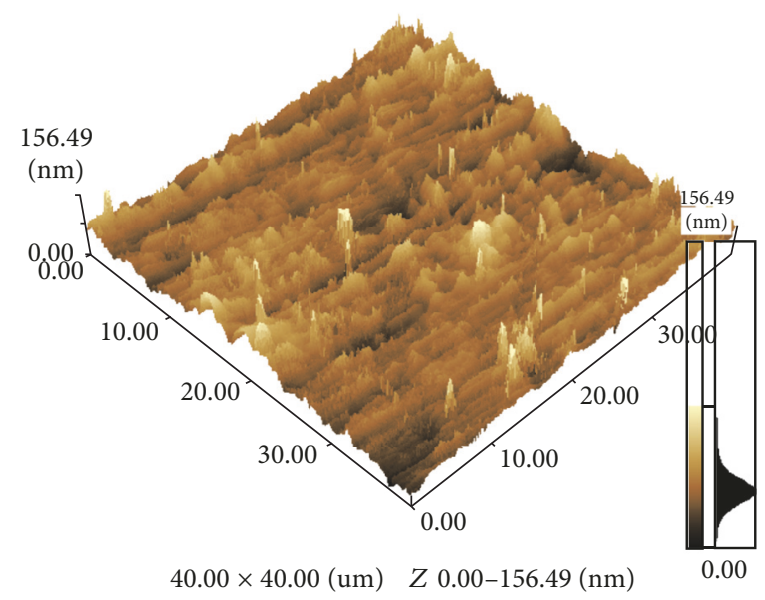

(a)

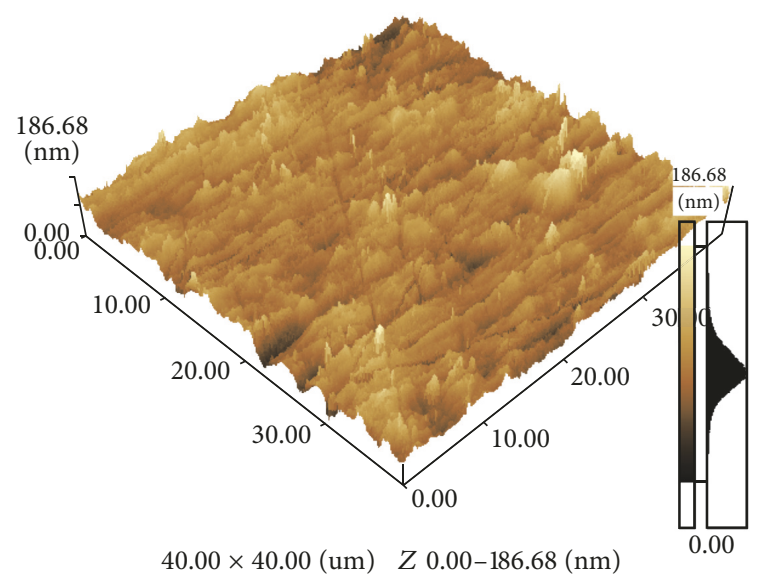

(b)

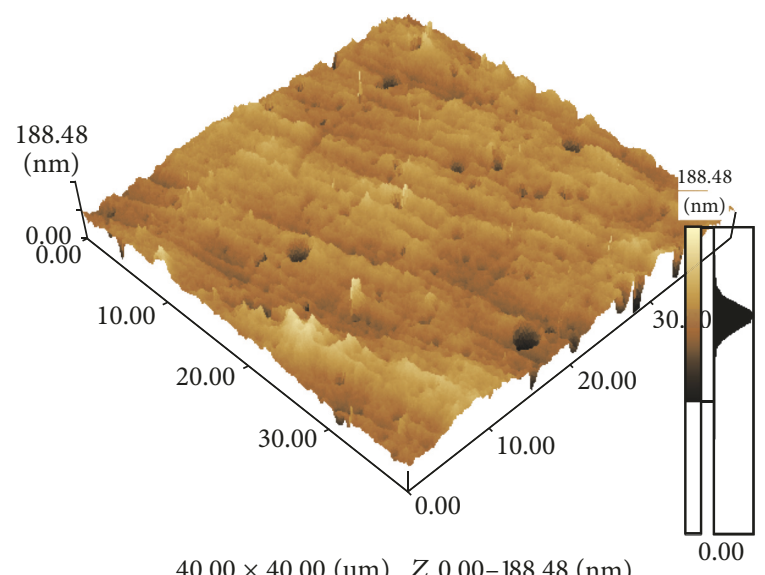

(c)

FIGURE 4: AFM images in surface morphology of PI films before and after surface modification with $1.0 \mathrm{~g} / \mathrm{L} \mathrm{TiO}_{2}$ dispersed solution for $30 \mathrm{~min}, \mathrm{UV}$ power: (a) $0 \mathrm{~W}$, (b) $100 \mathrm{~W}$, and (c) $300 \mathrm{~W}$.

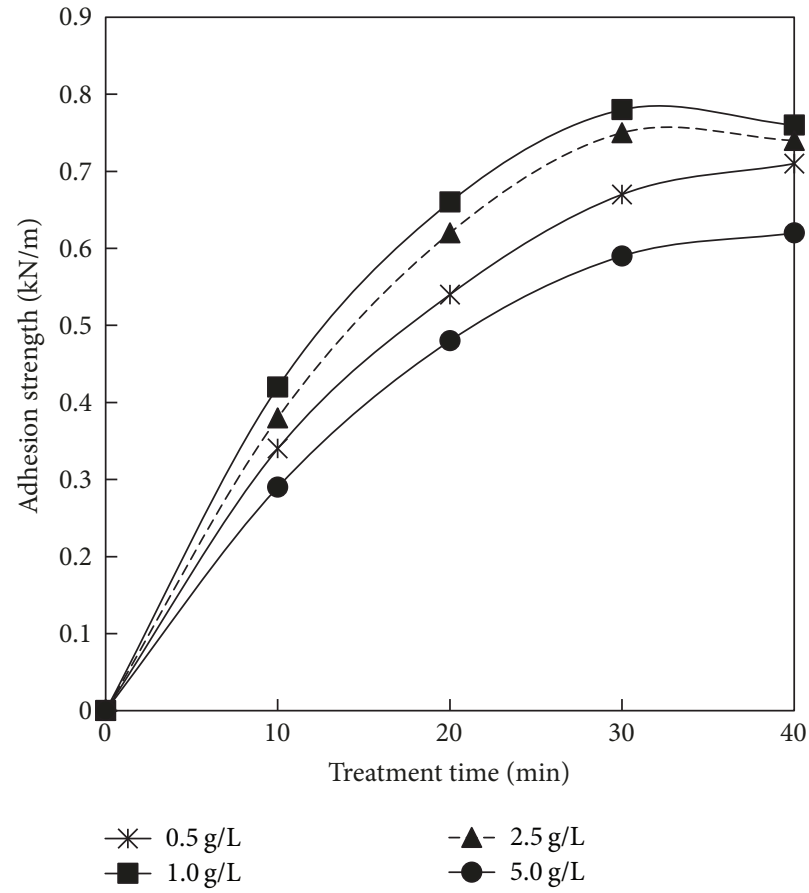

FIGURE 5: Dependence of the adhesion strength upon the $\mathrm{TiO}_{2}$ content and the treatment time under $300 \mathrm{~W}$ UV light. 


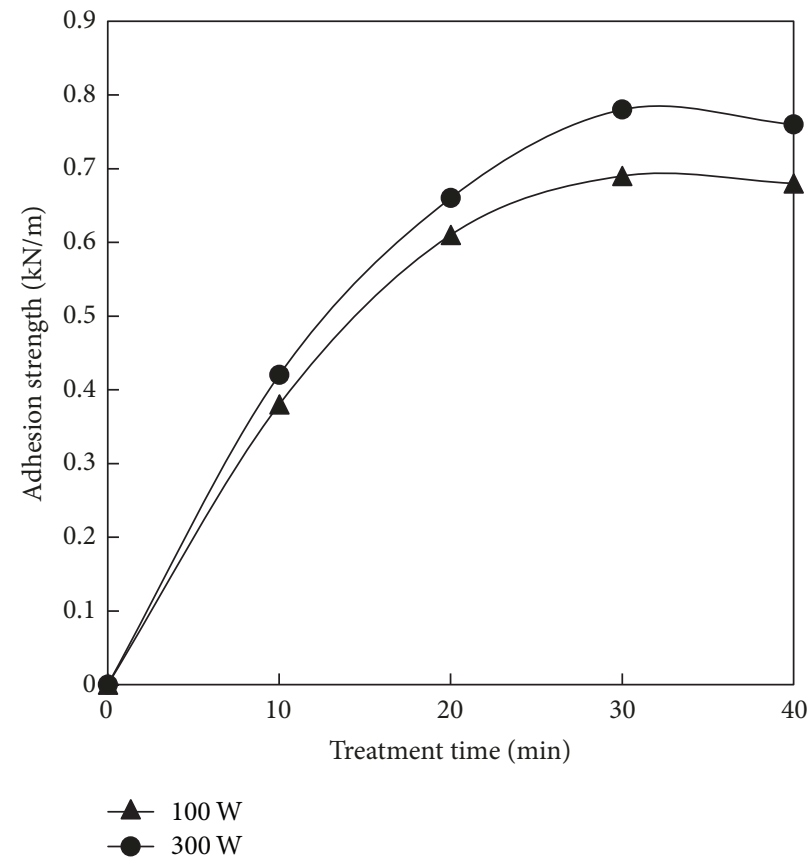

FIGURE 6: Dependence of the adhesion strength upon the UV power and the treatment time at the $\mathrm{TiO}_{2}$ content of $1.0 \mathrm{~g} / \mathrm{L}$.

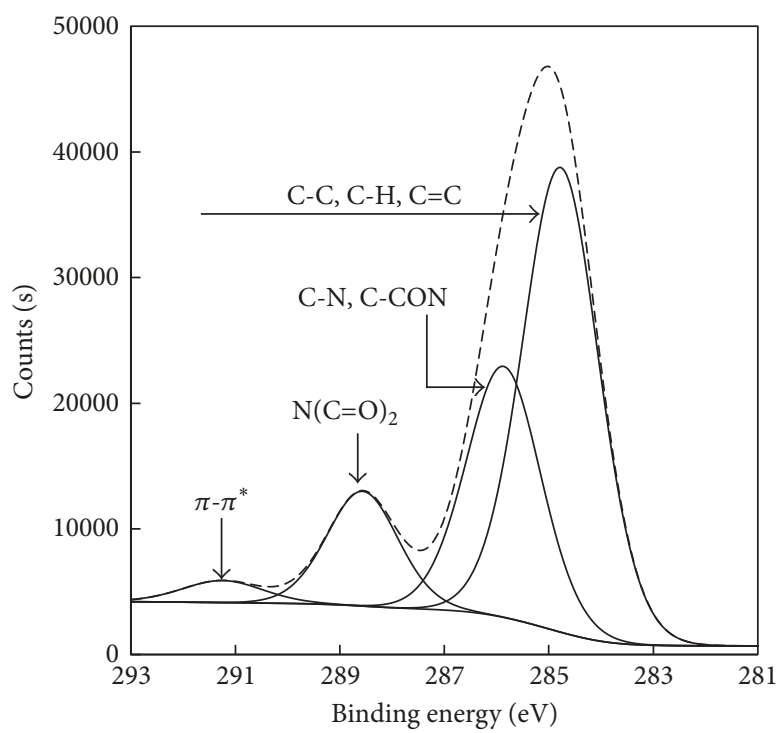

(a)

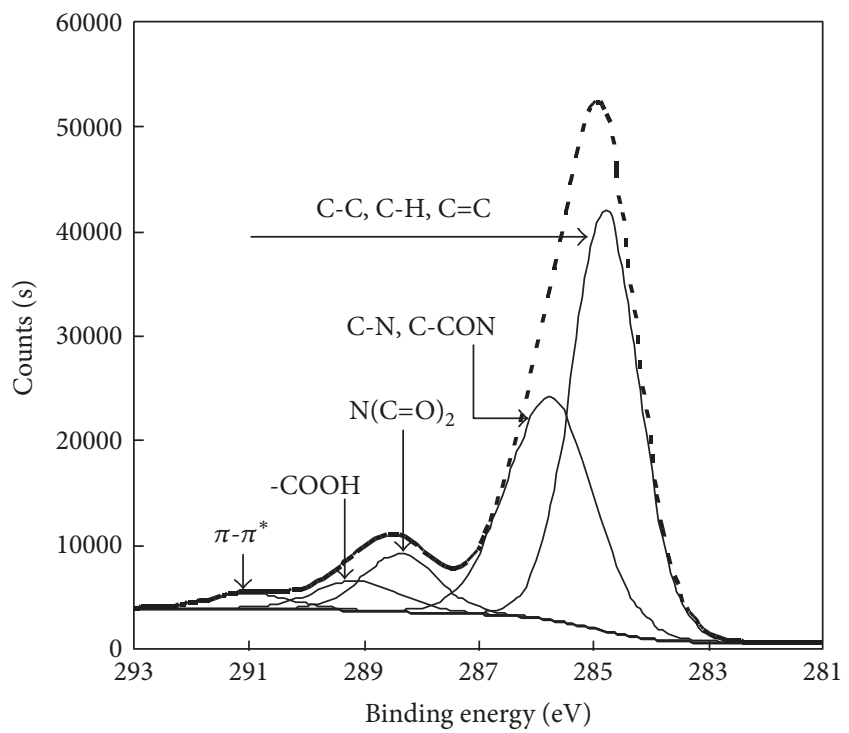

(b)

FIgURE 7: The C1s XPS spectra of the PI films before and after surface modification with $1.0 \mathrm{~g} / \mathrm{L} \mathrm{TiO}_{2}$ dispersed solution for 30 min under 300 W UV light. (a) The C1s XPS spectra of the PI films before surface modification. (b) The C1s XPS spectra of the PI films after surface modification.

carbon group contents of the PI films before and after being treated for $30 \mathrm{~min}$ under different UV powers and $1.0 \mathrm{~g} / \mathrm{L}$ $\mathrm{TiO}_{2}$ content are shown in Table 3 .

When the UV power increased from $0 \mathrm{~W}$ to $300 \mathrm{~W}$, the content of hydrophobic groups $(\mathrm{C}-\mathrm{H} / \mathrm{C}-\mathrm{C} / \mathrm{C}=\mathrm{C})$ decreased from $53.7 \%$ to $46.5 \%$, that of the $\mathrm{N}(\mathrm{C}=\mathrm{O})_{2}$ group decreased from $14.8 \%$ to $6.8 \%$, and that of C-O/C-N and $\pi-\pi^{*}$ groups showed almost no change. However, the content of hydrophilic groups (-COOH) increased from $0 \%$ to $6.1 \%$, indicating that partial bonds of the PI film were cleaved and that amide and carboxyl groups formed on the surface of PI films after treatment with $\mathrm{TiO}_{2}$. Given that carboxyl and amide groups can coordinate with the copper atom, their quantities can affect the adhesion strength of copper film to the PI film [28]. As a result, the high contents of $-\mathrm{COOH}$ groups enhanced the surface hydrophilicity of the PI film and 
TABLE 3: The contents of carbon groups on the PI film surface before and after photocatalytic treatment (treatment time: $30 \mathrm{~min} \mathrm{C}_{\mathrm{TiO}_{2}}$ : $1.0 \mathrm{~g} / \mathrm{L})$.

\begin{tabular}{|c|c|c|c|c|c|}
\hline UV power & $\mathrm{C}-\mathrm{C}, \mathrm{C}-\mathrm{H}, \mathrm{C}=\mathrm{C}(\%)$ & $\mathrm{C}-\mathrm{O}, \mathrm{C}-\mathrm{N}(\%)$ & $\mathrm{N}(\mathrm{C}=\mathrm{O})_{2}(\%)$ & $\pi-\pi^{*}(\%)$ & $-\mathrm{COOH}(\%)$ \\
\hline 0 & 53.7 & 38.7 & 14.8 & 2.8 & 0 \\
\hline $100 \mathrm{~W}$ & 48.0 & 37.6 & 7.3 & 2.2 & 4.9 \\
\hline $300 \mathrm{~W}$ & 46.5 & 38.3 & 6.8 & 2.3 & 6.1 \\
\hline
\end{tabular}

thus improved the adhesion strength between the electroless copper film and the PI film.

\section{Conclusion}

An environmentally friendly and effective photocatalytic treatment method was used to modify PI films. The effects of $\mathrm{TiO}_{2}$ content, treatment duration, and UV power on the surface hydrophilicility and adhesion strength of the modified PI film were investigated through surface contact angle measurements, SEM observation, AFM, and XPS. The surface hydrophilicity and the adhesion strength of the photocatalytically treated PI film increased with increasing UV power and prolonged treatment duration. Surface modification with $1.0 \mathrm{~g} / \mathrm{L} \mathrm{TiO}_{2}$ suspension was more effective than with other $\mathrm{TiO}_{2}$ contents under $300 \mathrm{~W}$ of UV power. High $\mathrm{TiO}_{2}$ content facilitated the aggregation of $\mathrm{TiO}_{2}$ particles, thus decreasing the oxidative capacity of the hydroxyl radicals generated by the $\mathrm{TiO}_{2}$ suspension. Under the optimal conditions of photocatalytic treatment, the adhesion strength between the electroless copper film and the PI film reached $0.78 \mathrm{kN} / \mathrm{m}$, and the surface topography and the surface roughness of the PI film slightly changed. XPS results indicated that surface oxygen content increased with prolonged treatment duration and increased UV power. Meanwhile, the surface carbon content decreased with prolonged treatment duration because the content of $-\mathrm{COOH}$ polar group increased. Photocatalytic treatment enhanced the surface hydrophilicity of PI film, thus resulting in high adhesion strength between the PI film and electroless copper film.

\section{Conflicts of Interest}

The authors declare that there are no conflicts of interest regarding the publication of this article.

\section{Authors' Contributions}

Wenxia Zhao and Zenglin Wang contributed equally to this paper.

\section{Acknowledgments}

This work was partially supported by the Natural Science Foundation of China (Grants nos. 21561027 and 21273144), the Science and Technology Innovation Leading Talent Project of Ningxia Hui Autonomous Region (Grant no. Ning Ke Chuang Word [2016] 12), the Excellent Youth Teacher Training Fund Project for Institution of Higher Education of Ningxia (Grant no. NGY2016195), National Grade Academic
Technical Leader of Ningxia Youth Top-Notch Talent (Office of Human Resources and Social Security of Ningxia Grant no. [2017] 787), Liupanshan Resources Engineering Technology Center (Grant no. HGZD17-03), and Key Disciplines of Inorganic Chemistry (Grant no. [2017] 83).

\section{References}

[1] K. S. Y. Lau, "High-Performance Polyimides and High Temperature Resistant Polymers," Handbook of Thermoset Plastics, pp. 297-424, 2013.

[2] I. A. Ronova, M. Bruma, and H.-W. Schmidt, "Conformational rigidity and dielectric properties of polyimides," Structural Chemistry, vol. 23, no. 1, pp. 219-226, 2012.

[3] D. Serbezeanu, I.-D. Carja, M. Bruma, and I. A. Ronova, "Correlation between physical properties and conformational rigidity of some aromatic polyimides having pendant phenolic groups," Structural Chemistry, vol. 27, no. 3, pp. 973-981, 2016.

[4] S. Joshi, A. v. Loon, A. Savov, and R. Dekker, "Adhesion Improvement of Polyimide/PDMS Interface by Polyimide Surface Modification," MRS Advances, vol. 1, no. 01, pp. 33-38, 2016.

[5] K. Fatyeyeva, A. Dahi, C. Chappey et al., "Effect of cold plasma treatment on surface properties and gas permeability of polyimide films," RSC Advances, vol. 4, no. 59, pp. 31036-31046, 2014.

[6] Y. Zhang, E. T. Kang, K. G. Neoh et al., "Surface plasma characterization of polyimide films for flexible electronics," Advanced Materials Research, vol. 970, pp. 132-135, 2014.

[7] A. B. Meddeb, Z. Ounaies, and M. Lanagan, "Enhancement of electrical properties of polyimide films by plasma treatment," Chemical Physics Letters, vol. 649, pp. 111-114, 2016.

[8] W. Kaczorowski, W. Szymanski, D. Batory, and P. Niedzielski, "Effect of plasma treatment on the surface properties of polydimethylsiloxane," Journal of Applied Polymer Science, vol. 132, no. 11, Article ID 41635, 2015.

[9] S.-H. Bang, "Improvement of NiMoNb to polyimide adhesion by inductively coupled nitrogen plasma treatment," Applied Surface Science, vol. 360, pp. 553-558, 2016.

[10] M. Akram, K. M. B. Jansen, L. J. Ernst, and S. Bhowmik, "Atmospheric plasma modification of polyimide sheet for joining to titanium with high temperature adhesive," International Journal of Adhesion and Adhesives, vol. 65, pp. 63-69, 2016.

[11] J. Won, M. H. Kim, Y. S. Kang et al., "Surface modification of polyimide and polysulfone membranes by ion beam for gas separation," Journal of Applied Polymer Science, vol. 75, no. 12, pp. 1554-1560, 2000.

[12] R. Mikšová, A. Macková, H. Pupikova, P. Malinský, P. Slepička, and V. Švorčík, "Compositional, structural, and optical changes of polyimide implanted by $1.0 \mathrm{MeV} \mathrm{Ni}+$ ions," Nuclear Instruments and Methods in Physics Research Section B: Beam Interactions with Materials and Atoms, vol. 406, pp. 199-204, 2017. 
[13] F. J. Xu, J. P. Zhao, E. T. Kang, and K. G. Neoh, "Surface functionalization of polyimide films via chloromethylation and surface-initiated atom transfer radical polymerization," Industrial \& Engineering Chemistry Research, vol. 46, no. 14, pp. 48664873, 2007.

[14] Z. Wu, D. Wu, W. Yang, and R. Jin, "Preparation of highly reflective and conductive metallized polyimide films through surface modification: Processing, morphology and properties," Journal of Materials Chemistry, vol. 16, no. 3, pp. 310-316, 2006.

[15] K. Akamatsu, S. Ikeda, H. Nawafune, and H. Yanagimoto, "Direct patterning of copper on polyimide using ion exchangeable surface templates generated by site-selective surface modification," Journal of the American Chemical Society, vol. 126, no. 35, pp. 10822-10823, 2004.

[16] L. Li, Y. Ma, J. Xie et al., "Metallization Process of a Polyimide Surface with Palladium-Free Activation for Electronic Field Applications," Journal of Electronic Materials (JEM), vol. 44, no. 10, pp. 4042-4051, 2015.

[17] I. Ghosh, J. Konar, and A. K. Bhowmick, "Study of palladium catalyzation for electroless copper plating on polyimide film," Journal of Nanoscience \& Nanotechnology, vol. 13, no. 1, pp. 517522, 2013

[18] Z. Wang, A. Furuya, K. Yasuda et al., "Adhesion improvement of electroless copper to a polyimide film substrate by combining surface microroughening and imide ring cleavage," Journal of Adhesion Science and Technology, vol. 16, no. 8, pp. 1027-1040, 2002.

[19] Y. I. Lee, Y. S. Goo, K. J. Lee, Y. G. Hwang, and Y. Byun, "Selective $\mathrm{Cu}$ patterning on polyimide using UV surface treatment and electroless plating," Journal of Photopolymer Science \& Technology, vol. 28, no. 2, pp. 157-161, 2015.

[20] Y.-I. Lee, Y.-S. Goo, K.-J. Lee et al., "Effect of UV/ozone treatment on interactions between ink-jet printed $\mathrm{Cu}$ patterns and polyimide substrates," Thin Solid Films, vol. 519, no. 20, pp. 6853-6857, 2011.

[21] T. Kondo, R. Watanabe, Y. Shimoyama, K. Shinohe, S. A. Kulinich, and S. Iwamori, "Effect of reactive oxygen species generated with ultraviolet lamp and plasma on polyimide surface modification," Surface and Interface Analysis, vol. 49, no. 11, pp. 1069-1077, 2017.

[22] H. Schmidt, M. Naumann, T. S. Müller, and M. Akarsu, "Application of spray techniques for new photocatalytic gradient coatings on plastics," Thin Solid Films, vol. 502, no. 1-2, pp. 132137, 2006.

[23] R. R. Thomas, "Wetting kinetics study of modified polyimide surfaces containing ionizable functional groups," Langmuir, vol. 19, no. 14, pp. 5763-5770, 2003.

[24] Z. Wang, O. Yaegashi, H. Sakaue, T. Takahagi, and S. Shingubara, "Suppression of native oxide growth in sputtered TaN films and its application to $\mathrm{Cu}$ electroless plating," Journal of Applied Physics, vol. 94, no. 7, pp. 4697-4701, 2003.

[25] L. Chen, B. Liao, J. Yu et al., "Study of adhesion strength of electroplated copper to polyimide using different types of tie layers," Nanoscience and Nanotechnology Letters (NNL), vol. 7, no. 3, pp. 240-247, 2015.

[26] D. M. Brewis, "Electroless copper plating onto polyimide using polymer nanosheet as a nano-adhesive," Polymer Journal, vol. 39, no. 1, pp. 41-47, 2007.

[27] K.-S. Chou, X.-Y. Chen, and I.-H. Lai, "Surface Roughness on Adhesion of Silver Colloids to a Polyimide Substrate," International Journal of Adhesion and Adhesives, vol. 92, no. 6, pp. 429439, 2016.
[28] T. Kondo, R. Watanabe, Y. Shimoyama, K. Shinohe, S. A. Kulinich, and S. Iwamori, "Effect of reactive oxygen species generated with ultraviolet lamp and plasma on polyimide surface modification," Surface Interface Analysis, vol. 49, no. 11, pp. 1069-1077, 2017. 

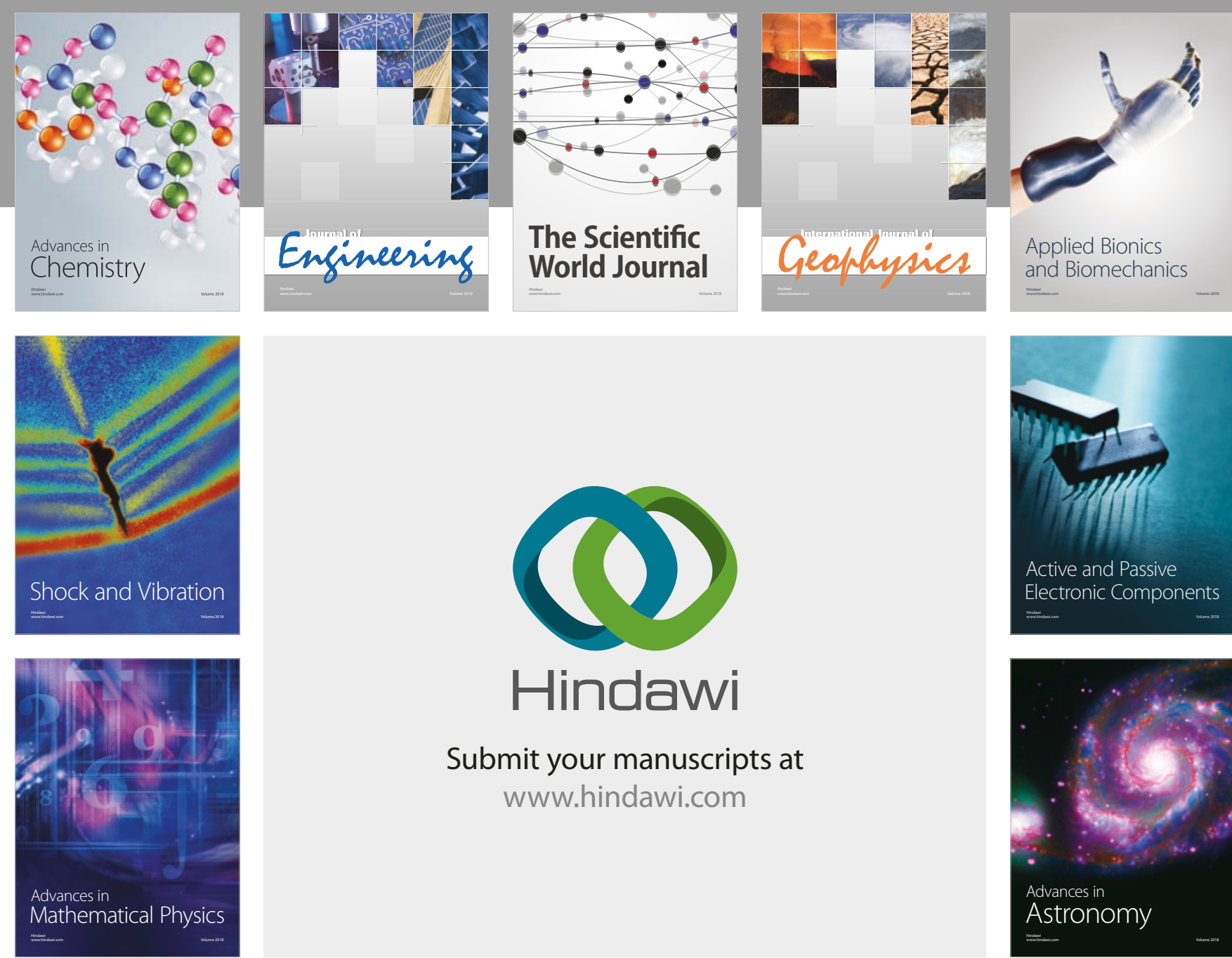

Submit your manuscripts at

www.hindawi.com

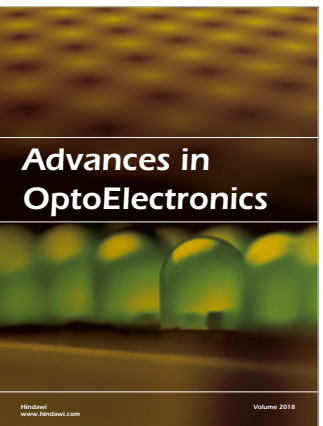

\section{Rotcting Machinery}
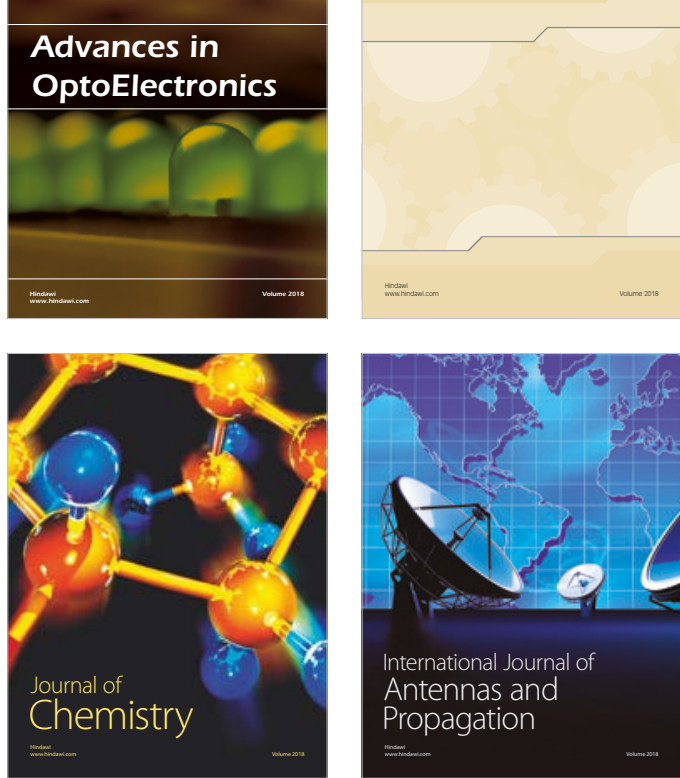

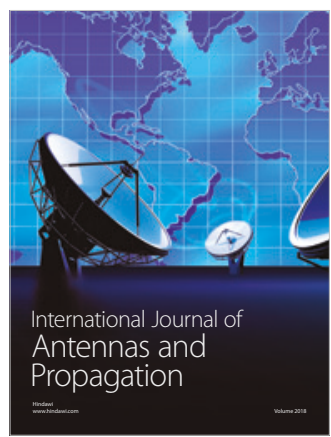

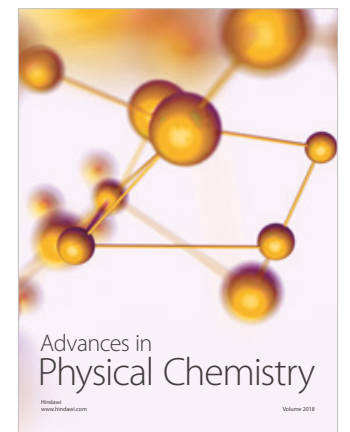

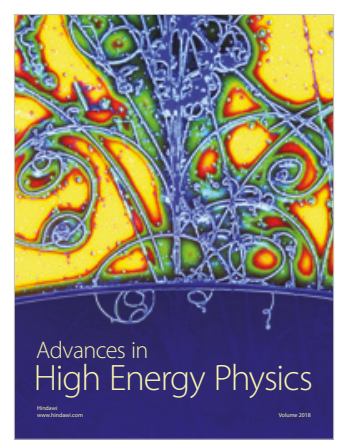

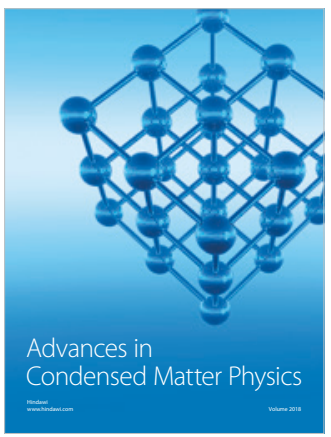

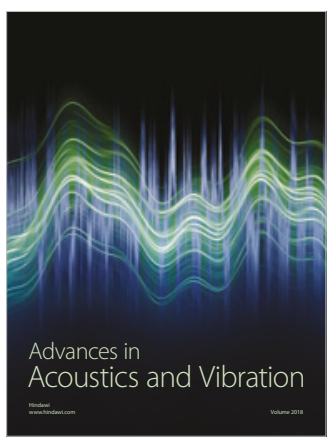

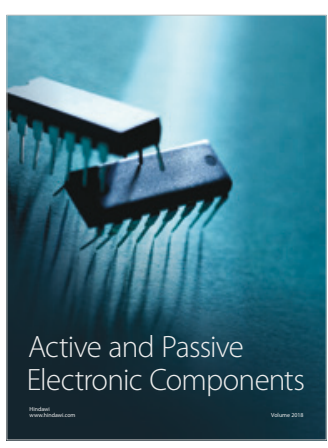
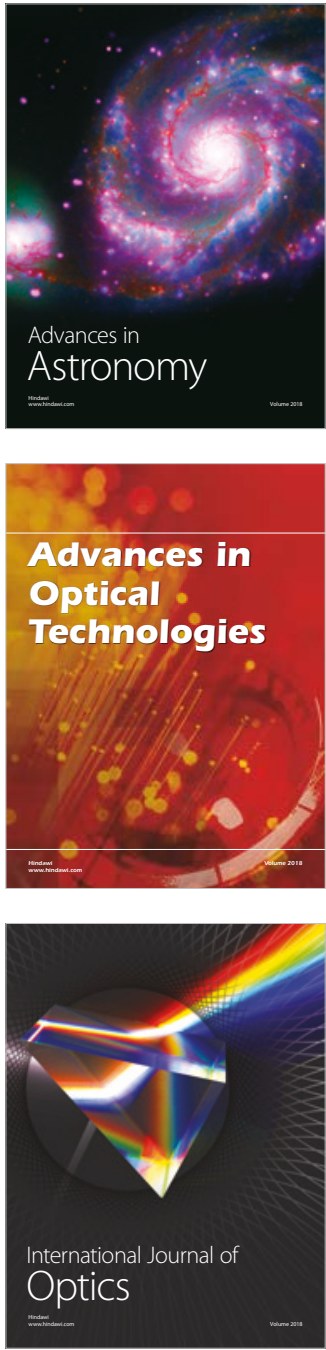